\title{
Efeito do diferimento sobre a produção de forragem e composição química do gramalote (Axonopus scoparius Fluggüe) Kuhlm.
}

\author{
Newton de Lucena Costa ${ }^{1}$, João Avelar Magalhães ${ }^{2}$, Valdinei Tadeu Paulino ${ }^{3}$, Claudio Ramalho
} Townsend $^{4}$, Antônio Neri Azevedo Rodrigues ${ }^{5}$, Guilherme de Lira Sobral Silva ${ }^{6}$

${ }^{1}$ Eng. Agr., D.Sc., Embrapa Roraima. Boa Vista, Roraima.

${ }^{2}$ Médico Veterinário, D.Sc., Embrapa Meio-Norte. Parnaíba, Piauí.

${ }^{3}$ Eng. Agr., Ph.D., Instituto de Zootecnia. Nova Odessa, São Paulo.

${ }^{4}$ Zootecnista, D.Sc., Embrapa Clima Temperado. Pelotas, Rio Grande do Sul.

${ }^{5}$ Eng. Agr., M.Sc.,. Doutorando UFPR, Curitiba, Paraná.

${ }^{6}$ Médico Veterinário, Pos-doutorando em Zootecnia na UFC. Fortaleza, Ceará.

*Autor para correspondência, E-mail: newtonlucena@yahoo.com.br

\begin{abstract}
RESUMO. O efeito da época de diferimento sobre a produção e composição química da forragem do gramalote (Axonopus scoparius Fluggüe (Kuhlm.) durante a estação seca, foi avaliado em experimento conduzido em Porto Velho, Rondônia. O delineamento experimental foi em blocos casualizados com parcelas divididas e três repetições. As épocas de diferimento ( 28 de fevereiro, 28 de março e 28 de abril) representavam as parcelas principais e os períodos de utilização (30 de junho, 30 de julho, 30 de agosto e 30 de setembro) as subparcelas. Os resultados obtidos sugerem a viabilidade do diferimento de pastagens de A. scoparius, no final do período chuvoso, de modo a acumular forragem para a suplementação dos rebanhos durante o período seco. A maior produção de matéria seca (MS) foi verificada com o diferimento em fevereiro, vindo a seguir o em março. Utilizações em setembro ou agosto forneceram os maiores rendimentos de MS. Independentemente das épocas de diferimento, observou-se redução significativa $(\mathrm{P}<0,05)$ dos teores de proteína bruta e coeficientes de digestibilidade in vitro da MS com o aumento da idade das plantas. O diferimento em abril com utilizações em junho e julho proporcionou forragem com maiores teores de proteína bruta. Os maiores coeficientes de digestibilidade in vitro da MS foram registrados com o diferimento em abril e utilização em junho. Visando conciliar rendimento e qualidade de forragem, recomenda-se o seguinte esquema: diferimento em março para utilizações em junho e julho e, diferimento em abril para utilizações em agosto e setembro.
\end{abstract}

Palavras chave: Digestibilidade, matéria seca, proteína bruta

Effects of pasture recuperation times on forage yield and chemical composition of Axonopus scoparius Fluggüe (Kuhlm.) pastures

\begin{abstract}
An experiment was conducted in Porto Velho, Rondônia, with the purpose of determining the best time for pasture recuperation and utilization of the forage accumulated of (Axonopus scoparius Fluggüe (Kuhlm.) for herd supplementation during dry season. The experimental design was randomized complete blocks (split-plot) with three replicates. The periods of recuperation began on February 28, March 28 and April 28 and constituted the main plots and, the utilization months (June 30, July 30, August 30 and September 30) the subplots. The data indicate the feasibility of differing grazing of the grass, during the rainy season, to provide forage for herd supplementation in the dry season. The higher dry matter (DM) yields were obtained with the pasture stockpiled in February, followed by March and utilizations in September or August. The grass, irrespective of differing dates, showed reductions $(\mathrm{P}<0.05)$ in crude protein $(\mathrm{CP})$ contents and in vitro DM digestibility toward the later utilization time. The stockpiled in April and utilizations in June or July provided forage with higher CP concentrations. The highest coefficients of in vitro DM were registered with the stockpiled in April and utilization in June. In order to obtain greater forage yields with better quality, it is suggested that
\end{abstract}


recuperation begin in March for pasture utilization in June or July, and in April for pasture utilization in August or September.

Keywords: crude protein, digestibility, dry matter

\section{Introdução}

Em Rondônia, as pastagens cultivadas representam a principal fonte para a alimentação dos rebanhos, as quais na sua maioria são formadas por gramíneas. Durante a estação chuvosa, devido à alta disponibilidade e valor nutritivo da forragem, observa-se desempenho satisfatório dos animais. No entanto, na época seca ocorre o oposto e, como consequência, há perda de peso dos animais ou redução drástica na produção de leite (Costa, 2004).

A conservação do excesso de forragem produzida durante o período chuvoso, sob a forma de feno ou silagem, embora constitua solução tecnicamente viável, é uma prática ainda inexpressiva no estado (Costa et al., 2014; Rodrigues Junior et al., 2015). A utilização do diferimento ou reserva de pastos durante a estação chuvosa surge como alternativa para corrigir ou equilibrar a defasagem da produção de forragem durante o ano (Andrade, 1993; Lalman et al., 2000). O diferimento consiste em suspender a utilização da pastagem durante parte de seu período vegetativo, de modo a favorecer o acúmulo de forragem para utilização durante a época seca. As plantas forrageiras mais indicadas para essa prática são aquelas que apresentam baixo acúmulo de colmos e boa retenção de folhas verdes, o que resulta em menores reduções no valor nutritivo ao longo do tempo (Euclides et al., 1992). Pesquisas com diversas gramíneas forrageiras tropicais demonstraram a viabilidade desta prática de manejo, desde que sejam selecionadas espécies adequadas para períodos de diferimento e utilizações específicas (Davis et al., 1987; Andrade \& Salgado, 1992; Costa, 2004; Euclides et al., 2007; Fonseca \& Santos, 2009).

O presente trabalho teve por finalidade avaliar o efeito de épocas de diferimento sobre a produção e composição química da forragem do gramalote (Axonopus scoparius Fluggüe (Kuhlm.), durante o período seco, nas condições ecológicas de Porto Velho, Rondônia.

\section{Material e Métodos}

O ensaio foi conduzido no Campo Experimental da Embrapa Rondônia, localizado no município de Porto Velho (96,3 m de altitude, $8^{\circ} 46^{\prime}$ de latitude sul e $63^{\circ} 5^{\prime}$ de longitude oeste). $\mathrm{O}$ clima da região é tropical úmido do tipo Am, com precipitação anual de $2.200 \mathrm{~mm}$, estação seca bem definida (junho a setembro); temperatura média anual de $24,9^{\circ} \mathrm{C}$ e umidade relativa do ar de $89 \%$.

O solo da área experimental é um Latossolo Amarelo, textura argilosa, fase floresta, com as seguintes características químicas: $\mathrm{pH}=5,1 ; \mathrm{Al}=$ $2,64 \mathrm{cmol}_{\mathrm{c}} / \mathrm{dm}^{3} ; \mathrm{Ca}+\mathrm{Mg}=1,28 \mathrm{cmol}_{\mathrm{c}} / \mathrm{dm}^{3} ; \mathrm{P}=$ $2 \mathrm{mg} / \mathrm{kg}$ e $\mathrm{K}=65 \mathrm{mg} / \mathrm{kg}$. O delineamento experimental foi em blocos casualizados com parcelas divididas e três repetições. As épocas de diferimento ( 28 de fevereiro, 28 de março e 28 de abril) representavam as parcelas principais e, as épocas de utilização (30 de junho, 30 de julho, 30 de agosto e 30 de setembro) as sub parcelas. $\mathrm{O}$ plantio foi realizado através de estacas com três nós distribuídas horizontal e continuamente no leito dos sulcos, os quais eram espaçados de 0,8 $\mathrm{m}$ entre si. A adubação de estabelecimento constou da aplicação de $22 \mathrm{~kg}$ de $\mathrm{P} / \mathrm{ha}$, sob a forma de superfosfato triplo.

Os cortes foram realizados manualmente a uma altura de $20 \mathrm{~cm}$ acima do solo. Os parâmetros avaliados foram rendimento de matéria seca (MS), teores de proteína bruta (PB), utilizando-se o método micro-Kjeldahl. O coeficientes de digestibilidade in vitro da MS (DIVMS) foi determinada pela técnica descrita por Tilley \& Terry (1963).

\section{Resultados e Discussão}

A análise da variância revelou significância $(\mathrm{P}<0,05)$ para o efeito da interação épocas de diferimento $\mathrm{x}$ épocas de utilização. Quando o diferimento foi realizado em fevereiro os maiores rendimentos de MS foram obtidos com utilizações em agosto e setembro, enquanto que para o diferimento em março ou abril a utilização em setembro forneceu a maior produção de forragem. Independentemente das épocas de utilização, os maiores rendimentos de MS foram fornecidos com o diferimento em fevereiro, como consequência do maior período de tempo que as plantas têm para o acúmulo de forragem (Tabela 1). Do mesmo modo, Andrade (1993), respectivamente com capim-elefante cvs. Mineiro e Cameroon verificou que pastagens diferidas em 
fevereiro ou março e utilizadas em agosto ou setembro forneciam maiores rendimentos de forragem que aquelas diferidas em abril e utilizadas em junho ou julho. Em geral, as produções verificadas com utilizações em agosto ou setembro, independentemente das épocas de diferimento foram bastante satisfatórias, superando em mais de $300 \%$ aquelas reportadas por Costa (2004) para capineiras de gramalote, durante o período de estiagem, sem a utilização do diferimento.

Tabela 1. Rendimento de matéria seca (t/ha) de Axonopus scoparius e função das épocas de diferimento e utilização. Porto Velho, Rondônia, 2001/2003

\begin{tabular}{lccccc}
\hline $\begin{array}{l}\text { Época de } \\
\text { diferimento }\end{array}$ & \multicolumn{5}{c}{ Época de utilização } \\
\hline & Junho & Julho & Agosto & Setembro & Média \\
\hline Fevereiro & $8,11 \mathrm{aB}$ & $9,04 \mathrm{aB}$ & $13,66 \mathrm{aA}$ & $14,95 \mathrm{aA}$ & 11,44 \\
Março & $7,02 \mathrm{aC}$ & $8,86 \mathrm{aB}$ & $8,98 \mathrm{bB}$ & $10,75 \mathrm{bA}$ & 8,91 \\
Abril & $5,33 \mathrm{bD}$ & $6,18 \mathrm{cCD}$ & $7,09 \mathrm{cBC}$ & $9,35 \mathrm{cA}$ & 6,98 \\
\hline Média & 6,82 & 8,03 & 9,91 & 11,69 & \\
\hline
\end{tabular}

- Médias seguidas de mesma letra maiúscula na linha e minúscula na coluna não diferem pelo teste de Tukey $(\mathrm{P}>0,05)$.

Com relação aos teores de $\mathrm{PB}$, observou-se um decréscimo $(\mathrm{P}<0,05)$ à medida que se aumentava a idade das plantas (Tabela 2). Os maiores teores foram verificados com o diferimento em abril $(8,82 \%)$ e utilizações em junho $(8,95 \%)$ ou julho $(8,09 \%)$. Estes valores são superiores aos obtidos por Andrade (1993) e Costa (1989), ambos com capim-elefante e, por Costa (2004) com o gramalote submetido a diferentes intervalos de cortes. Considerando-se que teores de PB inferiores a 7\% são limitantes à produção animal, pois implicam em baixo consumo voluntário, menores coeficientes de digestibilidade e balanço nitrogenado negativo, verifica-se que a gramínea atenderia às exigências nutritivas mínimas dos animais, quando utilizada em junho, julho e agosto, independentemente das épocas de diferimento. Declínios significativos na percentagem de $\mathrm{PB}$, à medida que as plantas forrageiras maturam, foram reportados para diversas gramíneas (Davis et al., 1987; Euclides et al., 1990; Magalhães et al., 2009; Rodrigues et al., 2014).

Tabela 2. Teores de proteína bruta (\%) de Axonopus scoparius em função das épocas de diferimento e utilização. Porto Velho, Rondônia, 2001/2003

\begin{tabular}{lccccc}
\hline $\begin{array}{l}\text { Época de } \\
\text { diferimento }\end{array}$ & \multicolumn{5}{c}{ Época de utilização } \\
\hline & Junho & Julho & Agosto & Setembro & Média \\
\hline Fevereiro & 7,55 & 6,97 & 6,02 & 5,66 & $6,55 \mathrm{c}$ \\
Março & 8,87 & 8,00 & 7,11 & 6,23 & $7,55 \mathrm{~b}$ \\
Abril & 10,44 & 9,31 & 8,12 & 7,44 & $8,82 \mathrm{a}$ \\
\hline Média & $8,95 \mathrm{a}$ & $8,09 \mathrm{~b}$ & $7,08 \mathrm{~b}$ & $6,44 \mathrm{c}$ & \\
\hline
\end{tabular}

- Médias seguidas de mesma letra não diferem pelo teste de Tukey $(\mathrm{P}>0,05)$.

Os coeficientes de DIVMS foram significativamente afetados $(\mathrm{P}<0,05)$ pelas épocas de diferimento e utilização (Tabela 3). Os maiores valores foram registrados com o diferimento em abril $(57,01 \%)$ e utilização em junho $(58,09 \%)$. Estes resultados estão em concordância com os relatados por Davis et al. (1987) e Euclides et al. (1990) para diversas gramíneas forrageiras tropicais. A redução na digestibilidade da forragem, à medida que a planta envelhece, decorre de modificações estruturais no tecido vegetal, com elevação dos teores de fibra e lignina e redução dos teores de $\mathrm{PB}$, que dificultam a ação dos microrganismos do rúmen sobre a forragem ingerida (Crampton, 1960). Durante o período de utilização, independentemente das épocas de diferimento, verificou-se um decréscimo acentuado dos 
coeficientes de DIVMS, que em termos relativos foi de $0,070 \%$ por dia em julho versus junho; $0,097 \%$ por dia em agosto versus julho e, $0,064 \%$ por dia em setembro versus agosto. Esses valores são inferiores aos relatados por Minson (1971), Tabela 3. Coeficiente de digestibilidade in vitro da matéria seca (\%) de Axonopus scoparius em função das épocas de diferimento e utilização. Porto Velho, Rondônia, 2001/2003

\begin{tabular}{lccccc}
\hline $\begin{array}{l}\text { Época de } \\
\text { diferimento }\end{array}$ & \multicolumn{5}{c}{ Época de utilização } \\
\hline & Junho & Julho & Agosto & Setembro & Média \\
\hline Fevereiro & 56,12 & 53,45 & 50,01 & 49,15 & $52,18 \mathrm{c}$ \\
Março & 58,04 & 55,25 & 53,33 & 51,04 & $54,41 \mathrm{~b}$ \\
Abril & 60,11 & 59,23 & 55,63 & 53,06 & $57,01 \mathrm{a}$ \\
\hline Média & $58,09 \mathrm{a}$ & $55,98 \mathrm{~b}$ & $52,99 \mathrm{~b}$ & $51,08 \mathrm{c}$ & \\
\hline
\end{tabular}

- Médias seguidas de mesma letra não diferem pelo teste de Tukey $(\mathrm{P}>0,05)$.

\section{Conclusões}

1. Os resultados obtidos sugerem a viabilidade do diferimento de pastagens de Axonpus scoparius, no final do período chuvoso, de modo a acumular forragem para a suplementação dos rebanhos durante o período seco;

2. O diferimento em abril com utilizações em junho e julho proporcionou forragem com maiores teores de proteína bruta;

3. Os maiores coeficientes de DIVMS foram registrados com o diferimento em abril e utilização em junho;

4. Visando conciliar rendimento e qualidade de forragem, recomenda-se o seguinte esquema: diferimento em março para utilizações em junho e julho e, diferimento em abril para utilizações em agosto e setembro.

\section{Referências Bibliográficas}

Andrade, I. F. 1993. Efeito da época de vedação na produção e valor nutritivo do capimelefante (Pennisetum purpureum Schum.) cv. Mineiro. Revista da Sociedade Brasileira de Zootecnia, 22, 53-63.

Andrade, I. F. \& Salgado, J. G. F. 1992. Efeito da época de vedação do capim-elefante (Pennisetum purpureum Shum.) cultivar Cameroon sobre a produção e valor nutritivo. Revista da Sociedade Brasileira de Zootecnia, 21, 637-646.

Costa, N. de L. 2004. Formação, manejo e recuperação de pastagens em Rondônia. Porto Velho: Embrapa Rondônia. 215p. que estimou uma taxa diária de decréscimo na digestibilidade de gramíneas forrageiras tropicais em torno de $0,1 \%$ ao dia.

Costa, N. de L. Efeito da época de diferimento sobre a produção de forragem e composição química de capim-elefante cv. Cameroon. Porto Velho: Embrapa-UEPAE Porto Velho, 1989. 4p. (Comunicado Técnico, 83).

Costa, N. de L., Townsend, C. R., Pereira, R.G. A. \& Magalhães, J. A. 2014. Produtividade e composição química da Brachiaria humidicola sob diferimento nos cerrados de Rondônia. Pubvet (Londrina), 8, Art\#1693.

Crampton, E. W., Donefer, E., Lloyd, L. E. \& 1960. A nutritive value index for forages. Journal of Animal Science, 19, 538-555.

Davis, C. E., Jolley, V., Mooso, G., Robison, L. \& Horrocks, R. 1987. Quality of stockpiled bigalta limpograss forage at varying fertility levels. Agronomy Journal, 79, 229-235.

Euclides, V. P., Valle, C. B., Silva, J. M. \& Vieira, A. 1990. Avaliação de forrageiras tropicais manejadas para produção de fenoem-pé. Pesquisa Agropecuária Brasileira, 25, 393-407.

Euclides, V. P. B., Macedo, M. C. M. \& Oliveira, M. P. 1992. Avaliação de diferentes métodos de amostragem para estimar o valor nutritivo de forragens sob pastejo. Revista Brasileira de Zootecnia, 21, 691-702.

Euclides, V. P. B., Flores, R., Medeiros, R. N. \& Oliveira, M. 2007. Diferimento de pastos de braquiária cultivares Basilisk e Marandu, na região do Cerrado. Pesquisa Agropecuária Brasileira, 42, 273-280.

Fonseca, D. \& Santos, M. 2009. Diferimento de pastagens: Estratégias e ações de manejo. 
Simpósio de forragicultura e pastagem, 6, 6588.

Lalman, D. L., Taliaferro, C. M., Epplin, F. M., Johnson, C. R. \& Wheeler, J. S. 2000. Review: grazing stockpiled Bermudagrass as an alternative to feeding harvested forage. Journal of Animal Science, 79, 1-8.

Magalhães, J. A., Rodrigues, B. H. N., Carneiro, M. S., Andrade, A. C., Costa, N. de L., Pinto, M. S. C. \& Mochel Filho, W. J. E. 2009. Influência da adubação nitrogenada e idade de corte sobre os teores de proteína bruta e fibra em detergente neutro de três cultivares de capim-elefante. Revista Electrónica de Veterinaria, 10, 1-13.

Rodrigues, B. H. N., Andrade, A. C., Magalhães, J. A., Fernandes, P. D., Santos, F. J. S. \& Costa, N. de L. 2014. Produção e composição bromatológica do capim-Tanzânia (Panicum maximum) em diferentes idades de rebrotação. Pubvet (Londrina), 8, 257.
Rodrigues Junior, C. T., Carneiro, M. S. S., Magalhães, J. A., Pereira, E. S., Rodrigues, B. H. N., Costa, N. de L., Pinto, M. S. C., Pinto, A. P., Fogaça, F. H. S. \& Castro, K. N. C. 2015. Produção e composição bromatológica do capim-Marandu em diferentes épocas de diferimento e utilização. Semina. Ciências Agrárias, 36, p. 2141-2154.

Tilley, J. M. A. \& Terry, R. A. 1963. A two-stage technique for the in vitro digestion of forage crops. Grass and Forage Science, 18, 104111.

\section{Recebido em Dezembro 10, 2014}

Aceito em Maio 27, 2015

License information: This is an open-access article distributed under the terms of the Creative Commons Attribution License, which permits unrestricted use, distribution, and reproduction in any medium, provided the original work is properly cited. 